\title{
DROUGHT AND POPULATION MOBILITY IN RURAL ETHIOPIA
}

\author{
Clark Gray ${ }^{1}$ and Valerie Mueller ${ }^{2}$ \\ 1 University of North Carolina at Chapel Hill, Department of Geography, 205 Saunders Hall, \\ Campus Box 3220, Chapel Hill, NC 27599-3220, Phone: (919) 843-1010, Fax: (919) 962-1537, \\ Cell: (919) 960-5808, cgray@email.unc.edu, Alternate clarklgray@gmail.com \\ ${ }^{2}$ International Food Policy Research Institute
}

\begin{abstract}
Significant attention has focused on the possibility that climate change will displace large populations in the developing world, but few multivariate studies have investigated climateinduced migration. We use event history methods and a unique longitudinal dataset from the rural Ethiopian highlands to investigate the effects of drought on population mobility over a ten-year period. The results indicate that men's labor migration increases with drought and that land-poor households are most vulnerable. However, marriage-related moves by women also decrease with drought. These findings suggest a hybrid narrative of environmentally-induced migration that recognizes multiple dimensions of adaptation to environmental change.
\end{abstract}

\section{Keywords \\ population mobility; migration; drought; climate; Africa; Ethiopia}

\section{INTRODUCTION}

For agricultural and other natural resource-dependent households in the developing world, drought is an important negative shock that can undermine livelihoods and well-being despite the use of various coping strategies. In semi-arid countries of Sub-Saharan Africa, droughts are frequent and their effects are magnified by deep rural poverty, limited government capacity and exposure to additional political, economic and health shocks (Dercon et al. 2005; Kazianga \& Udry 2006). Historical, qualitative and anecdotal accounts indicate that migration and population mobility have been a common response to drought, as falling agricultural and animal production pushes households and individuals to seek new opportunities elsewhere (Hugo 1996; Laczko \& Aghazarm 2009). A growing concern is that climate change will magnify this process through increased rainfall variability, displacing millions of climate-induced migrants (Myers 2002; Warner et al. 2009). These predictions have been widely cited but also criticized for relying on sparse documentation (Black 2001; Kniveton et al. 2008), creating significant doubt as to the likely scope of the problem.

Fortunately, a small number of quantitative studies have recently provided new insight into these issues. These studies have combined large-scale household surveys, environmental

(C) 2011 Elsevier Ltd. All rights reserved.

Correspondence to: Clark Gray.

Publisher's Disclaimer: This is a PDF file of an unedited manuscript that has been accepted for publication. As a service to our customers we are providing this early version of the manuscript. The manuscript will undergo copyediting, typesetting, and review of the resulting proof before it is published in its final citable form. Please note that during the production process errors may be discovered which could affect the content, and all legal disclaimers that apply to the journal pertain. 
data sources and multivariate methods to convincingly address the consequences of drought and other environmental factors for population mobility ${ }^{1}$ (e.g., Halliday 2006; Massey et al. 2010). These studies confirm the importance of drought for mobility, but also indicate that household responses to drought are considerably more complex than is commonly assumed. Rural households have access to many strategies other than mobility with which to respond to drought (Roncoli et al. 2001), and in some cases drought can actually reduce mobility (Henry et al. 2004; Gray \& Bilsborrow 2010).

We contribute to this literature by investigating the consequences of drought for population mobility in the rural Ethiopian highlands. This region is of particular interest given its endemic poverty, high population pressure on land resources and exposure to recurrent droughts (World Bank 2005). To address this issue we draw on a unique longitudinal household survey, the Ethiopian Rural Household Survey (ERHS), which has repeatedly interviewed 1500 rural households since 1994 (Dercon \& Hoddinott 2009). We use data from the 1999, 2004 and 2009 rounds of the ERHS to construct mobility histories for 3,100 individuals, and then use discrete-time event history models to examine the effects of drought on mobility while controlling for baseline characteristics and additional communitylevel shocks. This period encompasses two severe droughts, in 2002 and 2008. Expanding on previous studies, we build multiple measures of drought using survey and satellite data sources and also test for nonlinear effects, multiple temporal lags and interactions with other characteristics. To examine the potential for multiple mobility strategies, we consider both the distance and motivation of moves and conduct the analysis separately for men and women.

Together, the results provide robust evidence that drought increases long-distance and laborrelated moves by men in Ethiopia but reduces marriage-related moves by women. Below, we interpret these results in the light of the Ethiopian cultural context and the ongoing debate about climate-induced migration. We conclude that this case complicates the traditional narrative of environmentally-induced migration by indicating that drought can both increase and decrease population mobility.

\section{HOUSEHOLD RESPONSES TO DROUGHT}

In the rural developing world, many households are reliant on natural resources for their livelihoods, including soil, water, plant and animal resources. Smallholder agriculturalists, such as those of highland Ethiopia, are particularly reliant on the timing and quantity of rainfall. Rainfall and other environmental factors tend to vary over time and space at a variety of scales in a manner not fully predictable by households, thereby potentially exposing them to environmental shocks such as drought which can undermine household well-being.

Fortunately, traditional resource use systems such as the grain and enset-centered agricultural systems of highland Ethiopia have been adapted over their long histories to repeated environmental shocks, and households can typically access a variety of strategies to both prepare for shocks (risk management strategies) and to respond to shocks (risk coping strategies) (Dercon 2002). Risk management strategies include asset accumulation, diversification of income sources, participation in risk-sharing networks and adoption of low-risk activities. Risk coping strategies include sales of assets, intensifying livelihood activities or adopting new ones, use of formal and informal credit, reducing non-essential expenditures and drawing on social networks and public programs for assistance. In

\footnotetext{
${ }^{1}$ We use the term migration when referring exclusively to long-distance moves and the term population mobility when referring collectively to all changes of residence.
} 
highland Ethiopia, rural households prepare for drought by accumulating livestock, planting drought-resistant crops, and participating in traditional risk-sharing networks (MezeHausken 2000; Little et al. 2006; Dercon et al. 2008). They can also respond to drought by selling livestock, drawing on assistance from networks, delaying marriage, and accessing publically available food aid and food-for-work programs (Webb 1993; Ezra 2001; Caeyers \& Dercon 2008).

Unfortunately, several problems commonly limit the utility of these strategies. Assets such as livestock are "lumpy" and cannot be subdivided, thus households may be reluctant to sell. Risk management strategies such as risk-sharing networks may have barriers to entry that exclude the most vulnerable. Additionally, when a common shock such as a drought affects a large area, the utility of risk-sharing networks is reduced and the value of assets may decline. Public assistance programs are often poorly targeted and late to arrive (Clay et al. 1999; Caeyers \& Dercon 2008). Due to these limitations and to deep-seated poverty, many rural households are not able to fully insure against shocks such as drought and thus suffer significant reductions in well-being (Dercon 2002; Kazianga \& Udry 2006). Gender and age biases can also magnify the effects of the shock for particular individuals within a household (Quisumbing 2003).

Given the limitations of these strategies for dealing with environmental shocks, an additional strategy that can be adopted by households or individuals either in preparation or response to shocks is migration or local mobility. In the rural developing world, the migration of an individual is often primarily a household-level decision, aimed at generating remittances and reducing total consumption in the origin household (Stark \& Bloom 1985). Migration allows diversification of income sources against risk across space and often across sectors of the economy (Rosensweig \& Stark 1989), and can help overcome capital market imperfections such as lack of credit and insurance (Taylor \& Martin 2001).

Nonetheless, migration as a coping strategy potentially suffers from many of the limitations described above: lack of access to capital or migrant networks can restrict participation (Curran \& Rivero-Fuentes 2003; Vanwey 2005). Employment opportunities in nearby destination areas may also decline following a large-scale shock, limiting the utility of local moves as a response to drought. Drought can also increase the costs of migration by making farm labor more valuable in the origin area, thus reducing the attractiveness of labor migration. Drought could additionally hinder marriage-related moves by reducing the availability of suitable marriage partners, inflating marriage costs such as dowries, and reducing access to the resources needed to finance a wedding (Rao 1993; Anderson 2003). For these reasons, drought could potentially reduce rather than increase both labor and marriage-related migration.

\section{PREVIOUS STUDIES}

Previous studies of environmentally-induced population mobility have largely focused on finding an appropriate terminology (Renaud et al. 2007), methodology (Kniveton et al. 2008), and legal framework (Conisbee \& Simms 2003) to consider this issue, as well as providing preliminary evidence of the nature of environmental effects (e.g., Jager et al. 2009). Early discussions of "environmental refugees" were explicitly Neo-Malthusian and predicted large-scale displacements based on the assumption that rural households had few other options with which to respond to environmental change (e.g., Myers 2002). Recent discussions have been more careful to acknowledge the substantial scope of human agency in responding to environmental change, the existence of significant barriers to migration, and the important role of economic and social factors in determining migration flows (Laczko \& Aghazarm 2009). Consequently, as this literature has rapidly grown over the past 
decade, predictions of large-scale human displacements have diminished and use of the term "environmentally-induced migrants" has become more common (Renaud et al. 2007).

Despite this high level of interest, as of yet few multivariate studies have attempted to evaluate environmental influences on population mobility. Scarcities of data on mobility and environmental conditions in the developing world, as well as institutional barriers between environmental studies and the social sciences, have contributed to this lacuna. Fortunately, a small number of recent studies have successfully used survey and environmental datasets and multivariate methods to investigate these effects. This approach allows controls for a variety of other factors which have been shown to influence migration and mobility, including age, gender, education, access to resources and migrant networks (Massey \& Espinosa 1997; White \& Lindstrom 2005).

At least five previous studies using quantitative approaches have investigated the consequences of drought and rainfall for population mobility. In an early study using descriptive approaches, Findley (1994) showed that that total migration did not increase during a drought in Mali, but did shift towards short-cycle migration and moves by women and children. More recent studies have used multivariate methods. Munshi (2003) found that international migration from southwestern Mexico to the United States decreased with rainfall, which he attributed to increased origin-area opportunities in rainfed agriculture. Henry et al. (2004) revealed that drought in Burkina Faso increased rural-rural migration by men but reduced their international migration as well as the rural-urban migration of women. Badiani and Safir (2008) showed that, in six villages in rural India, temporary migration decreased with rainfall for agricultural households and increased with rainfall for wage laboring households. Finally, Gray and Bilsborrow (2010) found that droughts in Ecuador increased local moves and international migration but decreased internal migration, perhaps due to the relative poverty of most internal migrants. Together these studies are largely consistent with the idea that when rainfall increases agricultural opportunities in the origin area, migration decreases from agricultural households. Nonetheless the Burkina Faso and Ecuador cases provide interesting counterexamples where drought decreased migration, perhaps reflecting a decline in access to the capital needed for costly migrations.

Multivariate studies have also investigated the migratory response to large-scale natural disasters. Halliday (2006) showed that a large earthquake in El Salvador had negative effects on international migration, likely because international migrants returned to work in damaged areas. Gray et al. (2009) found that the Indian Ocean tsunami in Indonesia led to high rates of displacement, but that potentially vulnerable households were not disproportionately affected. In the very different context of the United States, several studies have also examined migration after Hurricane Katrina, revealing that poor and AfricanAmerican households were disproportionately vulnerable to flood damage and long-term displacement (e.g., Stringfield 2009). These studies suggest that environmental shocks have complex effects on migration that are not fully consistent with the Neo-Malthusian narrative: adverse environmental conditions often increase migration by vulnerable populations, but not always.

Ethiopia is of particular interest in the study of environmentally-induced migration because of its deep poverty and long history of environmental, economic and political shocks. Our research builds on three previous studies which have examined migration in Ethiopia in context of war, famine and shifting rights to land. Berhanu and White (2000) used retrospective migration data for the period 1960-1989 to show that rural-urban migration by women increased during periods of armed conflict but was not affected by periods of famine. Ezra and Kiros (2001) used a similar approach to show that rural out-migration from 1984-1994 was higher from communities that were perceived to be more vulnerable to 
shocks. Finally, de Brauw and Mueller (2010) used the ERHS data described below to investigate the relationship between rural out-migration and the security of land tenure in an environment of changing land rights.

Our study contributes to these literatures by drawing on a unique panel dataset that includes 1500 households from a large geographic area over a ten-year period. Building on the richness of this data, we contribute three important innovations to the study of environmentally-induced population mobility. First, we consider both the distance and motivation of moves, improving on previous studies which have often treated all moves uniformly and/or ignored local and marriage-related moves. These moves represent a large proportion of population mobility and are likely to respond to drought differently than longer-distance and labor-related moves which have commonly been the focus of research. Second, we examine these processes separately for men and women, which is important because marital arrangements (Fafchamps \& Quisumbing 2005a) and labor participation rates differ significantly between men and women in Ethiopia (Quisumbing \& Yohannes 2005). By doing so, we contribute to a growing number of quantitative studies which consider how gendered social structures influence the process of migration (Davis \& Winters 2001; Curran \& Rivero-Fuentes 2003).

Our third core innovation relates to the measurement of drought, which previous studies have measured primarily via annual rainfall totals from weather stations (e.g., Munshi 2003). This approach ignores the timing of rainfall, which is equally important from an agronomic perspective, as well as the detailed environmental knowledge held by rural households (Meze-Hausken 2004). Instead, we draw on household self-reports of drought, satellite measures of daily rainfall, and a model predicting self-reported drought to build three alternative measures of drought and to test the robustness of our findings. This study thus adds to a small number of previous studies of migration which have drawn on both survey and spatial measures of environmental conditions (Gray 2009; Gray \& Bilsborrow 2010).

\section{THE ETHIOPIAN RURAL HOUSEHOLD SURVEY}

\section{(a) Data collection}

We use data from the Ethiopia Rural Household Survey (ERHS) which has collected panel data from approximately 1500 households from 15 rural communities over a fifteen-year period. The duration, sample size and geographic scope of this data collection make ERHS unique among household surveys from East Africa, and among a handful of such surveys in the developing world as a whole. The data were collected by the International Food Policy Research Institute, Oxford University, and Addis Ababa University and are publically available (Dercon \& Hoddinott 2009). The study communities (Figure 1) were originally selected as a judgment sample intended to be approximately representative of the rural highlands, and comparisons with the census indicate that the communities are similar to the rural highlands as whole (Dercon \& Hoddinott 2009). Data collection in the full set of fifteen communities began in 1994 and additional rounds were conducted in 1995, 1999, 2004 and 2009. Within the study communities, households were sampled through a stratified random sample, and then linked across rounds based on residence of the male head or, in his absence, the majority of household members. Attrition of the panel has been low at 1-2\% of households per year (Dercon \& Hoddinott 2009).

Data collection in each round included the implementation of a structured questionnaire in each sample household. This questionnaire collected information on demographic composition, assets, expenditures, agricultural activities, and other individual and household characteristics, and it retains many common elements across rounds. Previous studies using 
this dataset have investigated the consequences of shocks for household well-being (e.g., Dercon et al. 2005), participation in traditional risk-sharing networks (e.g., Dercon et al. 2008), and the impacts of development policies (e.g., Quisumbing 2003; Caeyers \& Dercon 2008), among other topics. Our analysis, described below, draws on the 1999, 2004 and 2009 rounds and specifically on histories collected in 2004 and 2009 of household exposure to shocks and the departure of household members.

\section{(b) Study areas}

From an agroecological perspective, the study communities are characterized by rugged topography, temperate to subtropical climates with seasonal rainfall, and a dependence on smallholder agriculture as the primary livelihood strategy. The communities range in elevation from $1200 \mathrm{~m}$ to $2900 \mathrm{~m}$ and in mean annual rainfall from $470 \mathrm{~mm}$ to $1300 \mathrm{~mm}$. Rainfall is highly seasonal, falling mostly during a summer kiremt season, the primary agricultural season, but in many areas also during a shorter spring belg season. Interannual variation in rainfall is also high, with droughts occurring in 1999, 2002-2003, 2005 and 2008, as well as earlier and with disastrous consequences in the mid-1980's (EMDAT 2010). Government food aid and food-for-work programs have been put in place, but are not able to fully relieve the effects of drought (Clay et al. 1999; Caeyers \& Dercon 2008).

Rural households are primarily dependent on smallholder agriculture, which is focused on the cultivation of grains in dryer areas (teff, barley, wheat, maize and sorghum) and on perennials in wetter areas (enset, coffee and khat) using animal traction or hoe plowing. Livestock are an important form of wealth, but the median household owned only the equivalent of two cattle in 2004. Following the nationalization of land in the 1970's, land legally belongs to the state but households have use rights that in many areas have been formalized through land registration and certification programs (Deininger et al. 2008). The population pressure on land is significant and the median household cultivated only 1 ha in 2004.

From a cultural perspective, the study communities are diverse and retain many traditional practices, as described by the survey data and a series of ethnographies conducted in the 1990's (Bevan \& Pankhurst 1996). More than ten ethnicities are represented in the sample as well as large numbers of Orthodox Christians, Catholics, Protestants and Muslims. Marriage practices differ significantly between ethnicities, but most commonly marriages are arranged by parents and both households provide gifts. The couple then moves to the husband's parents' household and later establishes an independent household drawing on land and livestock from the husband's family (Ezra 2003; Fafchamps \& Quisumbing 2005b). Polygamous marriages and/or divorce are accepted in some contexts. Men are the primary agricultural laborers but women also participate in many agricultural tasks in addition to providing the majority of labor for home production. Agricultural work is also regularly shared through traditional labor-sharing and oxen-sharing practices, but agricultural wage labor also occurs. The burden of risks such as illness is also shared through traditional burial societies, saving associations, religious societies and kin networks (Dercon et al. 2008).

From a development perspective, the study communities are characterized by severe poverty, lack of infrastructure, and low levels of migration. In both 2004 and 2009, 35-40\% of households reported insufficient food consumption in the previous month. Most homes are constructed of wood or mud with thatched roofs and dirt floors with a single sleeping area, and most communities do not have access to electricity, piped water or paved roads. Additionally, most household heads have no formal education and very few participate in non-agricultural wage labor. Significant long-distance rural-rural migration occurred during armed conflicts in the 1970's and as part of state-led resettlement schemes during the droughts of the 1980's. However subsequent governments placed significant restrictions on 
rural-urban migration, and current rates of migration and urbanization are low (Berhanu \& White 2000; World Bank 2005).

\section{ANALYSIS}

To investigate the effects of drought on mobility, we conducted an event history analysis through several steps as described below. First, we used the survey data described above to build a person-year dataset containing multiple measures of mobility. Second, we used aggregated household-level reports of drought and satellite measurements of rainfall to construct multiple measures of community-level drought. Third, we constructed several control variables at individual, household and community levels to account for other influences on mobility. Fourth, we examined the effects of drought on mobility while controlling for other factors by using multivariate event history models. Finally, we conducted an analysis of attrition among individuals in the panel.

\section{(a) Person-year dataset}

We first used the survey data described above to build a longitudinal dataset on individuals at risk of mobility. In the ERHS questionnaires, rosters collect information on both current household residents and previous household residents who have either departed or died, including on the timing and destination of departures. Using existing identifiers and a supplementary within-household age-sex match, we linked roster data on individuals resident in 1999 to roster data from the 2004 and 2009 surveys. We excluded one community (Sirbana Goditi), where individual identifiers were inconsistent across rounds, leaving 14 communities for the analysis. Individuals who were present in 1999 and were reported to have departed the origin household in 2004 or 2009 were considered to be movers ${ }^{2}$. We refer to these individuals as movers rather than migrants because some moved only a short distance, as described below. Consistent with previous studies (Berhanu \& White 2000; Ezra \& Kiros 2001), mobility occurred overwhelmingly among individuals aged 15-39 during the study period who were not the head of household or spouse of the head in 1999, and this population was defined to be at risk of mobility.

Individuals not at risk of mobility were excluded from the analysis, as were those died in the interval, departed the household before age 15, or were lost to follow-up after 1999 (see (e) Attrition). A small additional number were excluded who had missing data on the timing of mobility. Following these exclusions, the dataset contains 1,667 adult men and 1,454 adult women at risk of mobility, of whom 702 men and 711 women departed the household. This individual-level dataset was then converted into a person-year dataset in which each case is a year in the life of a person at risk for mobility. Individuals enter the dataset in 1999 or when they turn fifteen years old, and leave the dataset when they depart the household, turn forty years old, or are censored at data collection in 2009. Men contribute 9,268 personyears to the dataset and women contribute 7,435 person-years. The annual rate of mobility for men was $7.6 \%$ for men and $9.6 \%$ for women.

In addition to the dichotomous measure of mobility defined above, mobility was decomposed into two multinomial outcomes based on distance and motivation. Firstly, movers were classified as (1) having remained with the district (i.e., woreda) versus (2) having moved outside of the district. Men made 411 moves within the district and 284 outside the district, whereas women made 457 within-district moves and 247 out-of-district moves. Data on the distance of moves was missing for 7 men and 7 women. Secondly,

\footnotetext{
2 This definition excludes as movers individuals who departed and then returned prior to the subsequent survey round as data their movements was not collected. However only 5\% of movers who departed prior to 2004 had returned by 2009, suggesting that the number of returnees missed by this definition is low.
} 
movers were classified as (1) moving to initiate or search for employment (i.e., labor mobility), (2) moving in association with marriage (either to the spouse's origin household or to an independent household), or (3) making other kinds of moves, which were primarily for schooling or to live with other family members. Men made 226 labor-related moves, 266 marriage-related moves, and 206 other moves. Women made 108, 439 and 161 of these types of moves respectively. Data on the motivation of moves was missing for 4 men and 3 women. For both men and women, local moves were primarily for marriage $(60 \%$ of local moves by men, $75 \%$ by women) followed by "other" motivations ( $27 \%$ by men, $21 \%$ by women). For women, distant moves were also most commonly for marriage (39\%), followed by work (35\%), but among men distant moves were primarily made for work $(60 \%)$, followed by "other" reasons (32\%).

\section{(b) Measures of drought}

To examine the influences of drought on mobility, we constructed three measures of drought using the household survey data and satellite data on rainfall. Our primary measure of drought, drawing on the household survey, is the proportion of households in the community that reported exposure to a drought in the previous year $(t-1)$, multiplied by ten to produce a score that ranges from one to ten. Thus the mean value of 1.41 can be interpreted as $14.1 \%$ of households reporting a drought (Table 1). This measure draws on households' detailed knowledge of local environmental conditions. Additionally, by aggregating this measure to the community level, we construct a continuous measure of drought intensity and avoid the potential endogeneity of household drought reports to response strategies. Reported drought peaks in 2002 and 2008, with considerable variation in intensity across communities, which is consistent with other reports of drought intensity (EMDAT 2010) and with the dispersed locations and varying climates of the fourteen study communities. Given that most rain falls in the latter part of the Ethiopian year and mobility can occur at any time of year, we select the previous year's rainfall (i.e., a one year lag) as the primary specification, but as described below we also relax this assumption to allow multiple temporal lags as well as nonlinear effects.

To confirm the robustness of the effects of reported drought, we also test the effects of two additional community-level measures of drought incorporating direct measures of rainfall. As complete data was not available for weather stations near the study communities, we instead draw on satellite measures of rainfall from NASA's Prediction of Worldwide Energy Resources (POWER) dataset, which provides global daily precipitation values at 1 degree resolution from $1997-2009^{3}$ (White et al. 2008). These data were linked to the study communities using Global Positioning System points collected in the field. Three pairs of nearby communities were located in the same cells and thus received identical values. We summed rainfall values for July-October ${ }^{4}$, the primary agricultural season, and then transformed these annual totals into a normalized index ranging from zero to ten that increases with drought ${ }^{5}$, which we refer to as the rainfall deficit. The mean value of this measure is 5.06, and can be interpreted as representing rainfall at $94 \%$ of the community median. This measure is positively correlated with reported drought at $r=0.29$ with $p<$ 0.001 .

\footnotetext{
${ }^{3}$ At the time of preparation, rainfall data were not yet available for September and October of 2009. We interpolated July-October rainfall for 2009 by dividing the July and August rainfall by its mean proportion of the July-October total.

${ }^{4}$ The Ethiopian calendar, used by the study communities and the ERHS questionnaire, is distinct from the Gregorian calendar and begins in early September. We consider the July-October rains to occur in the earlier year as most rain falls in July and August.

$\left.\left.5_{\text {Rainfall deficit }=\left(2-\left(\text { rain }_{t c} / \text { median_rain }\right.\right.}\right)\right)^{*} 10-5$ where rain $t c$ is the July-October rainfall in community $c$ in year $t$, and median_rain $_{C}$ is the median July-October rainfall in community $c$.
} 
Finally, we also develop a third measure to address the potential limitations of both reported drought, which could reflect community-specific perception biases, and the rainfall deficit, which ignores the timing of rainfall within the rainy season. To do this we created a household-year dataset and used logistic regression to predict household's reports of drought as a function of community fixed effects and monthly rainfall totals for the previous two years, allowing for a lag in the perception of drought (results available upon request). The value predicted by this model, which we refer to as predicted drought, can be interpreted as the mean level of reported drought expected in the community based on recent rainfall and on stable community factors such the historical climate. This measure thus captures the cross-community relationship between the timing of rainfall and perceived drought, but is free of community-year specific factors that could have biased the perception of particular droughts (i.e., an unsuccessful collective response). Predicted drought is highly correlated with reported drought $(r=0.86, p<0.001)$ and has the same unit of measurement.

\section{(c) Control variables}

To account for other factors that might influence mobility, we also construct several control variables at individual, household and community scales in order to capture their previously described effects on mobility (Table 1) (White \& Lindstrom 2005). Time-invariant controls, measured in 1999, include whether the individual was a child of the household head, whether the household head was female, whether the head was an ethnic minority, whether a parent of the head was important to village social life, whether the head had formal schooling, the size of the household, the number of movers sent by the household between 1994 and 1999, agricultural land area, and the number of livestock owned by the household. These variables measure access to resources, economic and social status, and social networks in and outside of the community. Time-varying individual-level controls include age of the individual and whether the individual had children. The latter serves as a timevarying measure of marital status as a marital history was not collected. To account for other community-level shocks that might be correlated with drought, we include time-varying measures of exposure to the four most commonly reported shocks other than drought (constructed in the same way as reported drought): exposure to flooding, problems with agricultural or animal pests, problems with access to agricultural inputs (including high prices), and problems selling agricultural products (including low prices).

\section{(d) Event history models}

To test the effects of drought on mobility while controlling for other factors, we estimate a series of discrete-time event history models (Allison 1984). These models are appropriate to examine exposure over time to a single risk (dichotomous model) or to a mutually exclusive set of risks (multinomial model). The multinomial model includes one equation for each multinomial outcome beyond the reference category, which is no mobility. To account for baseline differences in mobility across communities, we include community fixed effects. We also include year fixed effects to account for changes in the national context and for artifacts arising from the timing of the surveys ${ }^{6}$.

In the multinomial model the log odds of experiencing a mobility event of type $r$ relative to no mobility (event $s$ ) are given by

$$
\log \left(\frac{\pi_{r i t}}{\pi_{s i t}}\right)=\alpha_{r t}+\alpha_{r c}+\beta_{r} X_{i t}
$$

\footnotetext{
${ }^{6} \mathrm{~A}$ community-year model indicates that the community and year fixed effects explain $58 \%$ of the variation in reported drought, indicating that considerable variation remains for us to explore in the model.
} 
where $\pi_{r i t}$ is the odds of mobility of type $r$ for individual $i$ in year $t, \pi_{s i t}$ is the odds of no mobility, $\alpha_{r t}$ is the baseline hazard of mobility of type $r$ in year $t, \alpha_{r c}$ is the baseline hazard of mobility of type $r$ in community $c, X_{i t}$ is a vector of predictor variables for individual $i$ in year $t, \beta_{r}$ is a vector of parameters for the effects of the independent variables on mobility of type $r$, and the types of mobility, $r$, are (1) within-district and out-of-district, and (2) labor, marriage and other. In the dichotomous version of this model, all forms of mobility are considered jointly.

All models include corrections for clustering at the level of the community to account for the non-independence of households in the same community and the use of community-level predictors (Angeles et al. 2005). For presentation, we exponentiate the coefficients of this model to produce odds ratios, which can be interpreted as the multiplicative effects of a unit increase in the predictor on the odds of the outcome relative to the reference outcome (i.e., no mobility). Due to the inclusion of fixed effects for the community and year, these coefficients can interpreted as comparing two individuals who are exposed to the same baseline community context as well as the same changing national context.

To fully explore the effects of drought using this approach, we estimate several dichotomous and multinomial models of mobility, always for men and women separately. First we estimate a simple dichotomous model incorporating the reported drought measure. Second we expand this model by allow interactions between reported drought and the individual and household-level controls, testing whether drought effects differ across subpopulations beyond men and women. Third, we return to the primary specification and estimate two multinomial models to examine how the effects or reported drought differ across the five types of mobility described above. Fourth, to test the robustness of these results, we reestimate the multinomial models with a variety of alternative specifications of drought. These include multiple temporal lags, nonlinear effects, and incorporation of the rainfall deficit and predicted drought measures described above. Finally, we use the nonlinear specification to estimate predicted probabilities of mobility under different drought conditions, providing an alternative estimate of the magnitude of drought effects on mobility.

\section{(e) Attrition}

A common problem in studies using panel data is attrition or loss to follow-up. In our case, mobility of individuals does not represent a loss to follow-up as departures are reported by remaining household members. However, attrition did occur in the form of the departure of entire households, individual mobility that was not reported, and miscoding of individual identifiers across rounds. Among individuals in the 1999 data who were at risk of mobility, $16 \%$ could not be linked to data from the 2004 and/or the 2009 rounds and were thus lost to follow-up. Among those lost to follow-up, $49 \%$ were part of whole households lost to follow-up, likely to due to mobility of the entire household.

To examine whether loss to follow-up is likely to bias our estimates of the effects of drought, we estimated logit models of individual and household-level attrition as influenced by baseline characteristics, community fixed effects, and (for individual attrition) the number of droughts reported by the household during the study period ${ }^{7}$ (results available upon request). Household attrition (i.e., the loss of an entire household) increased with education of the head and decreased with household size, consistent with the departure of small, well-educated households, but was not influenced by other baseline characteristics.

\footnotetext{
${ }^{7}$ Given that the exact timing of attrition is unknown, we introduce this alternative household-level measure of drought to allow withincommunity variation in exposure to drought.
} 
Individual attrition (i.e., the loss of an individual from a remaining household) was lower for children of the head and higher from larger households, consistent with both mobility and miscoding of individual identifiers, but was not influenced by other baseline characteristics. Individual attrition was also not influenced by the total number of droughts reported by the household for the 2000-2008 period, suggesting that our estimates of the effects of drought are not likely to be biased by attrition.

\section{RESULTS}

Below we describe the results of the event history analysis of mobility, considering in turn each of the five modeling steps described above. We comment on the effects of control variables when of interest but, consistent with the goals of the study, focus our interpretation on the effects of drought.

\section{(a) The dichotomous model}

Table 2 presents the results of the simple dichotomous model of mobility. For both men and women, the effects of control variables are jointly highly significant and consistent with previous studies of internal migration in the developing world. Mobility peaked at ages 30-49 for men and ages 25-29 for women. For both groups mobility was lower for children of the household head and individuals with children, reflecting stronger ties to the origin household. Mobility also increased with household size, indicating a crowding effect given that land and livestock resources are controlled. Additionally, men's mobility increased with the number of livestock and marginally decreased with pest problems, and women's mobility increased with problems obtaining agricultural inputs.

The effect of drought on mobility was positive and highly significant $(p=.002)$ for men, but negative and non-significant for women. For men, a 10\% rise in the proportion of the community reporting drought was matched by a $10 \%$ increase in the odds of mobility. This result is consistent with a simple model in which drought serves as a push factor for migration, particularly for men who are the primary labor migrants. Below, however, we complicate this story by allowing the effects of drought to differ between subpopulations and across different types of mobility.

\section{(b) Interactions with drought}

Table 2 also presents an expansion of the dichotomous model in which the effects of the individual and household-level controls are allowed to interact with drought, testing whether drought effects are the same across subpopulations. The interactions are jointly highly significant for both men and women. For women, the drought effect remains non-significant for the reference category but becomes significantly negative for women with children. The drought effect also becomes significantly larger for women ages 30-49 and for women in households with a female head, as well as smaller in households where a parent of the head was socially important in the village. For men, the main drought effect remains positive and significant but becomes smaller as household land area increases. These results suggest a more complex story in which certain groups are more affected by drought, particularly women with children, who move less often, and men from land-poor households, who move more often. In indicating that land-poor households are more vulnerable to climate-induced mobility, these results are also consistent with a growing literature on vulnerability to environmental change (Adger 2006).

\section{(c) Multinomial models}

Table 3 presents an additional extension of the dichotomous model by allowing the effects to differ across categories of mobility defined by distance and motivation. Due to space 
limitations we do not comment in detail on the effects of control variables but observe that overall they are consistent with expectations. Notable results for men include increases in local and marriage mobility with age and livestock, and increases in labor mobility with minority ethnicity and migrant networks. Notable results for women include decreases in labor mobility with land and livestock, and increases in labor mobility with minority ethnicity and problems obtaining agricultural inputs.

The multinomial approach reveals that the positive effects of drought on men's mobility are significant only for long-distance mobility (i.e., migration) and labor mobility, the odds of which increase $18 \%$ and $13 \%$ respectively with a $10 \%$ increase in the proportion reporting drought. This result suggests that men are responding to drought with long-distance and labor mobility in order to supplement household income, consistent with expectations. The effects of drought on women's mobility remain non-significant for most outcomes but become strongly negative for marriage mobility. This result suggests that, consistent with ethnographic reports (Ezra 2001), women's marriage mobility is delayed in times of drought to limit potentially high bride-wealth expenses associated with marriage (Fafchamps \& Quisumbing 2005b). That this effect is significant for women's marriage mobility but not men's can be explained by the fact that, as noted above, their marriage mobility commonly occurs at different times: women first move to the home of their father-in-law, and the couple later forms an independent household. This result provides an interesting counterexample to the dominant narrative of environmentally-induced migration given that mobility decreases with drought.

\section{(d) Alternative specifications of drought}

In Table 4, to test the robustness of these findings, we present four alternative specifications of the drought effects on the two multinomial outcomes. Overall, the results indicate the effects described above are quite robust to alternative specifications and measures of drought. Alternative specification 1 allows a nonlinear effect of reported drought on mobility. Reported drought values greater than 2.0 were considered to be moderate drought and values greater than 4.0 were considered to be severe drought, corresponding to the 70th and 90th percentiles respectively of the reported drought distribution at the community-year level. This specification reveals that the positive effects of drought on men's labor and longdistance mobility are primarily due to the consequences of severe drought, as expected given the right-skewed distribution of reported drought. For women, however, moderate drought has a larger negative effect on marriage migration than severe drought, and moderate drought also significantly reduces short-distance moves. These results suggest that the desire to lower the number of consumers in the origin household might partially counteract the desire to limit marriage-related expenses (perhaps to less-desirable spouses) in times of severe drought.

Alternative specification 2 returns to the linear specification of drought but allows effects of reported drought in year of mobility (year $t$ ) as well as from the previous year (year $t-1$ ). (We also tested for effects of drought from years prior to year $t-1$, but these were consistently non-significant and are not shown.) Specification 2 reveals that the significant positive effects of drought on men's labor mobility extend into the year of mobility, but that other effects year $t$ are marginally significant or non-significant. Alternative specifications 3-4 replace reported drought with the rainfall deficit and predicted drought respectively, but retain the year $t$ and year $t-1$ specification to allow lags in how deficits in rainfall are perceived as drought. Overall, the effects of these two measures of drought are qualitatively similar to those of reported drought, with a few notable differences. The positive effects of drought on men's labor and long-distance mobility occur primarily in year $t$ instead of year $t-1$, which may reflect mental "backdating" of perceived droughts to include earlier dry periods. For women, the previously non-significant effect of drought on short-distance 
mobility becomes significant and a positive effect of drought on (relatively rare) labor migration becomes evident, but the negative effect of drought on marriage mobility is robust to these changes.

\section{(e) Predicted probabilities of mobility}

Finally, in Table 5 we present predicted probabilities of mobility derived from the nonlinear model described above (alternative specification 1). These values provide a clearer view of the magnitude of differences in mobility under varying drought conditions. For men, this analysis reveals that, as conditions change from no drought to severe drought, the rate of total mobility increases from $5.7 \%$ to $9.8 \%$ of individuals per year, the rate of labor mobility increases from $1.4 \%$ to $2.6 \%$, and the rate of long-distance mobility increases from $1.7 \%$ to $4.8 \%$ (i.e., nearly triples). Among women, a change from no drought to moderate drought reduces total mobility from $8.3 \%$ to $5.5 \%$, short-distance mobility from $4.9 \%$ to $2.9 \%$, and marriage mobility from $4.8 \%$ to $2.6 \%$. Thus the magnitudes of drought effects on migration are relatively large, though not large enough to depopulate communities as envisioned under worse-case scenarios.

\section{CONCLUSIONS}

Our results provide robust evidence that drought has important consequences for population mobility in rural highland Ethiopia. Among men, labor-related movements and migration out of the district more than doubled under severe drought, with total mobility reaching $10 \%$ of adult men per year. Men from land-poor households were most vulnerable to these effects, presumably due to a lesser ability to cope with drought. These results support the common observation that mobility serves as a key coping strategy following drought, as well as the frequent assumption that the poor are most vulnerable to these effects. However, the results for women significantly complicate this story. Women's short-distance and marriage-related mobility were reduced by half under moderate drought, reflecting a decreased ability to finance wedding expenses and new household formation. These results emphasize the importance of nonlinear environmental effects on mobility, as well as the potential for environmental shocks to reduce instead of increase population mobility.

Together these results contribute to a pattern emerging from the small number of previous demographic studies of environmentally-induced population mobility: Adverse environmental conditions often increase mobility, but not always. Instead, consistent with migration theory, mobility remains selective with important barriers to participation, and adverse conditions can actually reduce mobility by undermining the necessary resources. The generality of this hybrid narrative of environmentally-induced population mobility is now supported by several quantitative studies (e.g., Henry et al. 2004; Halliday 2006; Gray 2009; Massey et al. 2010), and should give policy-makers pause before they accept the common narrative of inevitable large-scale displacement occurring under future climate change (e.g., Myers 2002; Warner et al. 2009). Regarding Ethiopia specifically, a warmer climate with more variable rainfall would likely accelerate the effects described here, but current models project higher rainfall for highland Ethiopia under future climate change (De Wit \& Stankiewicz 2006).

This study also has important implications for research methods in the field of environmentally-induced migration. Publications in this field are characterized by a very high ratio of review and theoretical papers to empirical analyses, with the former often arguing that there is no generalizable methodology for testing environmental influences on population mobility (e.g., Laczko \& Aghazarm 2009). We disagree and hope that other investigators will take note of the approach described here and apply it in new contexts, improving our ability to generalize. We use data from an unique long-term panel survey 
with specific questions about environmental shocks and supplement with additional geospatial data, but important progress can also be made using shorter-duration panel surveys (e.g., Halliday 2006) and specially designed retrospective surveys of migration (e.g., Henry et al. 2004). In many contexts, however, new data collection will be required, and we hope that these concerns will inform a new generation of longitudinal surveys that increasingly take environmental factors into account.

\section{Acknowledgments}

We thank the International Food Policy Research Institute, Addis Ababa University and Oxford University for providing access to the survey data, and the NASA Langley Research Center POWER Project for providing access to the rainfall data. While preparing this manuscript Clark Gray was supported by a grant from the National Institutes of Health (K99HD61752). We also thank Jason Bremner for providing helpful comments on an earlier draft.

\section{References}

Adger W. Vulnerability. Global Environmental Change. 2006; 16(3):268-281.

Allison, P. Event History Analysis. Thousand Oaks, CA: Sage Publications; 1984.

Anderson S. Why dowry payments declined with modernization in Europe but are rising in India. Journal of Political Economy. 2003; 111(2):269-310.

Angeles G, Guilkey DM, Mroz T. The impact of community-level variables on individual-level outcomes: Theoretical results and applications. Sociological Methods and Research. 2005; 34(1): 76-121.

Badiani, R.; Safir, A. Coping with aggregate shocks: Temporary migration and other labor responses to climatic shocks in rural India. Presentation to the European Society for Population Economics; Seville. June 11-13; 2008. http://espe.conference-services.net/resources/321/1533/pdf/ESPE2009_0392_paper.pdf

Berhanu B, White M. War, famine, and female migration in Ethiopia, 1960-1989. Economic Development and Cultural Change. 2000; 49(1):91-113.

Bevan, P.; Pankhurst, A. Ethiopian village studies. Centre for the Study of African Economies. 1996. www.csae.ox.ac.uk/evstudies/main.html

Black, R. Environmental refugees: Myth or reality? United Nations High Commissioner for Refugees. 2001. Working Paper No. 34. www.unhcr.org/3ae6a0d00.html

Caeyers, B.; Dercon, S. Political connections and social networks in targeted transfer programmes: Evidence from rural Ethiopia. Center for the Study of African Economies. 2008. Working Paper 2008-33. www.csae.ox.ac.uk/workingpapers/pdfs/2008-33text.pdf

Clay D, Molla D, Habtewold D. Food aid targeting in Ethiopia: A study of who needs it and who gets it. Food Policy. 1999; 24(4):391-409.

Conisbee, M.; Simms, A. Environmental Refugees: The Case for Recognition. New Economics Foundation; London: 2003. www.neweconomics.org/publications/environmental-refugees

Curran S, Rivero-Fuentes E. Engendering migrant networks: The case of Mexican migration. Demography. 2003; 40(2):289-307. [PubMed: 12846133]

Davis B, Winters P. Gender, networks, and Mexico-US migration. Journal of Development Studies. 2001; 38(2):1-26.

De Brauw, A.; Mueller, V. Do limitations in land rights transferability influence low mobility rates in Ethiopia?. Paper presented to the Centre for the Study of African Economies Conference; March 21-23; Oxford. 2010. www.csae.ox.ac.uk/conferences/2010-EDiA/papers/081-Mueller.pdf

Deininger K, Ali D, Holden S, Zevenbergen J. Rural land certification in Ethiopia: Process, initial impact, and implications for Other African Countries. World Development. 2008; 36(10):17861812.

Dercon S. Income risk, coping strategies, and safety nets. The World Bank Research Observer. 2002; 17(2):141-166. 
Dercon, S.; Hoddinott, J. International Food Policy Research Institute; 2009. The Ethiopian Rural Household Surveys 1989-2004: Introduction. www.ifpri.org/dataset/ethiopian-rural-household-surveys-erhs-1989-2004

Dercon, S.; Hoddinott, J.; Krishnan, P.; Woldehanna, T. Collective Action and vulnerability: Burial societies in rural Ethiopia. 2008. CAPRi Working Paper No. 83. www.capri.cgiar.org/wp/capriwp83.asp

Dercon S, Hoddinott J, Woldehanna T. Shocks and consumption in 15 Ethiopian Villages, 1999-2004. Journal of African Economies. 2005; 14(4):559-585.

De Wit M, Stankiewicz J. Changes in surface water supply across Africa with predicted climate change. Science. 2006; 311(5769):1917-1921. [PubMed: 16513946]

EMDAT. Université Catholique de Louvain; Brussels, Belgium: 2010. The OFDA/CRED international disaster database. www.emdat.net

Ezra M. Demographic responses to environmental stress in the drought- and famine-prone areas of northern Ethiopia. International Journal of Population Geography. 2001; 7(4):259-279.

Ezra M. Factors Associated with Marriage and Family Formation Processes in Southern Ethiopia. Journal of Comparative Family Studies. 2003; 34(4):509-530.

Ezra M, Kiros G. Rural out-migration in the drought prone areas of Ethiopia: A multilevel analysis. International Migration Review. 2001; 35(3):749-771. [PubMed: 19186413]

Fafchamps M, Quisumbing A. Assets at marriage in rural Ethiopia. Journal of Development Economics. 2005a; 77(1):1-25.

Fafchamps M, Quisumbing A. Marriage, bequest and assortative matching in rural Ethiopia. Economic Development and Cultural Change. 2005b; 53(2):347-380.

Findley S. Does drought increase migration? A study of migration from rural Mali during the 1983-1985 drought. International Migration Review. 1994; 28(3):539-553. [PubMed: 12345794]

Gray C. Environment, land and rural out-migration in the southern Ecuadorian Andes. World Development. 2009; 37(2):457-468.

Gray, C.; Bilsborrow, R. Environmental influences on out-migration in rural Ecuador. Paper presented to the Population Association of America; Dallas. April 15-17; 2010. http://paa2010.princeton.edu/abstractViewer.aspx?SubmissionId=101839

Gray, C.; Frankenberg, E.; Gillepsie, T.; Sumantri, C.; Thomas, D. Tsunami-induced displacement in Sumatra, Indonesia. Paper presented to the International Union for the Scientific Study of Population; Marrakech. September 27-October 2; 2009. http://iussp2009.princeton.edu/abstractViewer.aspx?submissionId=90318

Halliday T. Migration, risk, and liquidity constraints in El Salvador. Economic Development and Cultural Change. 2006; 54(4):893-925.

Henry S, Schoumaker B, Beauchemin C. The impact of rainfall on the first out-migration: A multilevel event-history analysis in Burkina Faso. Population and Environment. 2004; 25(5):423-460.

Hugo G. Environmental concerns and international migration. International Migration Review. 1996; 30(1):105-131.

Jager, J.; Fruhmann, J.; Grunberger, S.; Vag, A. Environmental Change and Forced Migration Scenarios Project Synthesis Report. Deliverable D.3.4 for the European Commission. 2009. www.each-for.eu/documents/EACH-FOR_Synthesis_Report_090515.pdf

Kazianga H, Udry C. Consumption smoothing? Livestock, insurance, and drought in rural Burkina Faso. Journal of Development Economics. 2006; 79(2):413-446.

Kniveton, D.; Schmidt-Verkerk, K.; Smith, C.; Black, R. Climate Change and Migration: Improving Methodologies to Estimate Flows. International Organization for Migration; 2008.

Laczko, F.; Aghazarm, C. Migration, environment and climate change: Assessing the evidence. International Organization for Migration; 2009.

Little P, Stone M, Moguesc T, Castrod A, Negatue W. 'Moving in place': Drought and poverty dynamics in South Wollo, Ethiopia. Journal of Development Studies. 2006; 42(2):200-225.

Massey D, Axinn W, Ghimire D. Environmental change and out-migration: Evidence from Nepal. Population and Environment. 2010; 32(2-3):109-136. [PubMed: 21350676] 
Massey D, Espinosa K. What's driving Mexico-U.S. migration? A theoretical, empirical, and policy review. American Journal of Sociology. 1997; 102(4):939-999.

Meze-Hausken E. Migration caused by climate change: How vulnerable are people in dryland areas? A case-study in northern Ethiopia. Mitigation and Adaptation Strategies for Global Change. 2000; 5(4):379-406.

Meze-Hausken E. Contrasting climate variability and meteorological drought with perceived drought and climate change in northern Ethiopia. Climate Research. 2004; 27(1):19-31.

Munshi K. Networks in the modern economy: Mexican migrants in the U.S. Labor Market. Quarterly Journal of Economics. 2003; 118(2):549-599.

Myers N. Environmental refugees: A growing phenomenon of the 21st century. Philosophical Transactions of The Royal Society B. 2002; 357(1420):609-613.

Quisumbing A. Food aid and child nutrition in rural Ethiopia. World Development. 2003; 31(7):13091324.

Quisumbing, A.; Yohannes, Y. How fair is workfare? Gender, public works, and employment in rural Ethiopia. World Bank Policy Research Working Paper No 3492. 2005. http://go.worldbank.org/NEUEOD9XP0

Rao V. The rising price of husbands: A hedonic analysis of dowry increases in rural India. Journal of Political Economy. 1993; 101(3):666-677.

Renaud, F.; Bogardi, J.; Dun, o; Warner, K. Control, adapt or flee: How to face environmental migration? 2007. United Nations University Institute for Environment and Human Security, InterSecTions No. 5. www.ehs.unu.edu/article:345

Roncoli C, Ingram K, Kirshen P. The costs and risks of coping with drought: livelihood impacts and farmers' responses in Burkina Faso. Climate Research. 2001; 19(2):119-132.

Rosenzweig M, Stark O. Consumption smoothing, migration, and marriage: Evidence from rural India. Journal of Political Economy. 1989; 97(4):905-926.

Stark O, Bloom D. The new economics of labor migration. American Economic Review. 1985; 75(2): 173-178.

Stringfield J. Higher ground: an exploratory analysis of characteristics affecting returning populations after Hurricane Katrina. Population and Environment. 2009; 31(1-3):43-63.

Taylor, J.; Martin, P. Human capital: Migration and rural population change. In: Rausser, G.; Gardner, B., editors. Handbook of Agricultural Economics. Elsevier Science; New York: 2001.

VanWey L. Land ownership as a determinant of international and internal migration in Mexico and internal migration in Thailand. International Migration Review. 2005; 39(1):141-172.

Warner K. Global environmental change and migration: Governance challenges. Global Environmental Change. 2010; 20(3):402-413.

Warner, K.; Ehrhart, C.; de Sherbinin, A.; Adamo, S.; Chai-Onn, T. In search of shelter: Mapping the effects of climate change on human migration and displacement. 2009. www.ciesin.columbia.edu/documents/clim-migr-report-june09_final.pdf

Webb P. Coping with drought and food insecurity in Ethiopia. Disasters. 1993; 17(1):33-47. [PubMed: 20958756]

World Bank. Well-being and poverty in Ethiopia: The role of agriculture and agency. 2005 Report No. 29468-ET.

White J, Hoogenboom G, Stackhouse P, Hoell J. Evaluation of NASA satellite-and assimilation model-derived long-term daily temperature data over the continental US. Agricultural and Forest Meteorology. 2008; 148(10):1574-1584.

White, M.; Lindstrom, D. Internal migration. In: Poston, D.; Micklin, M., editors. Handbook of Population. New York: Kluwer Academic Publishers; 2005. 


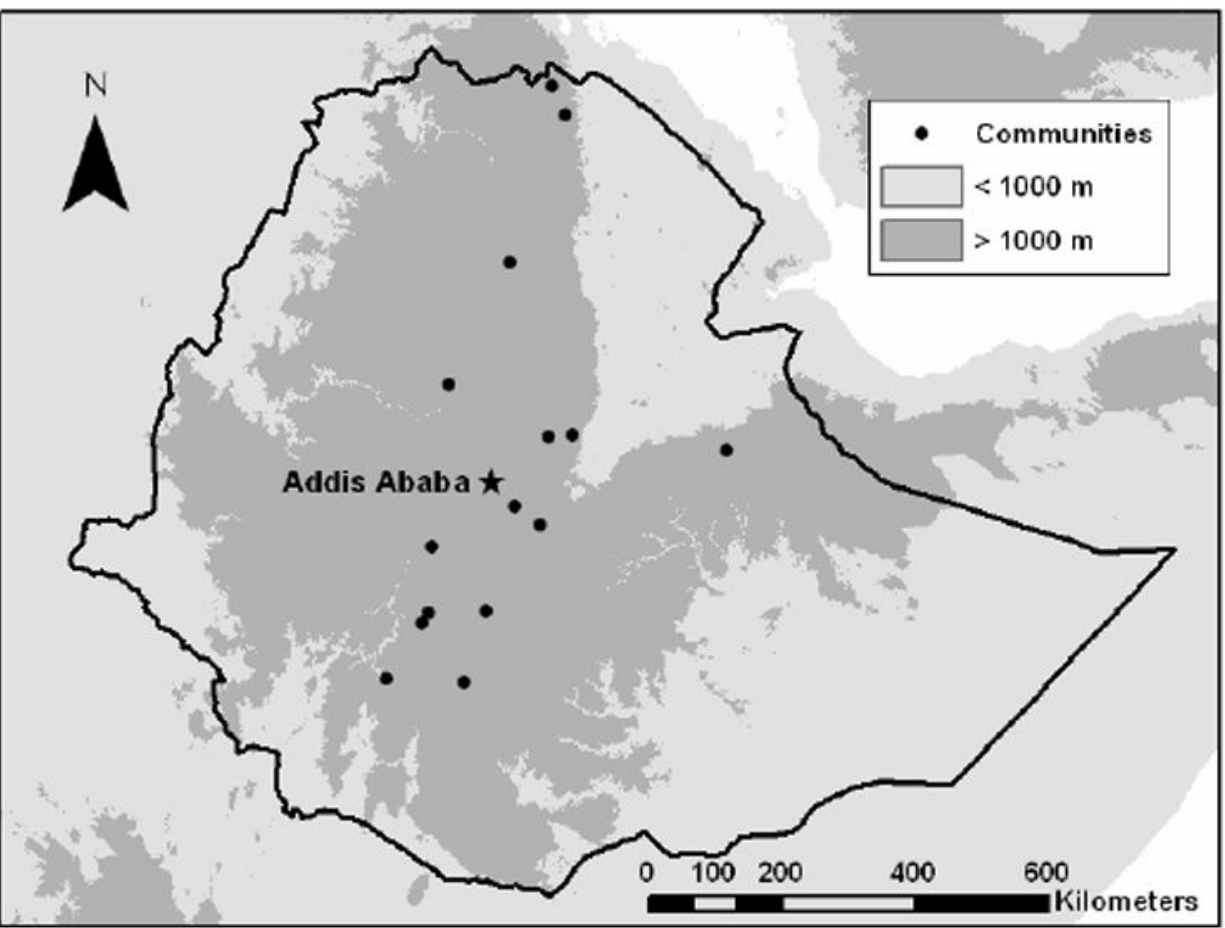

Figure 1.

Map of Ethiopia with the study communities. 


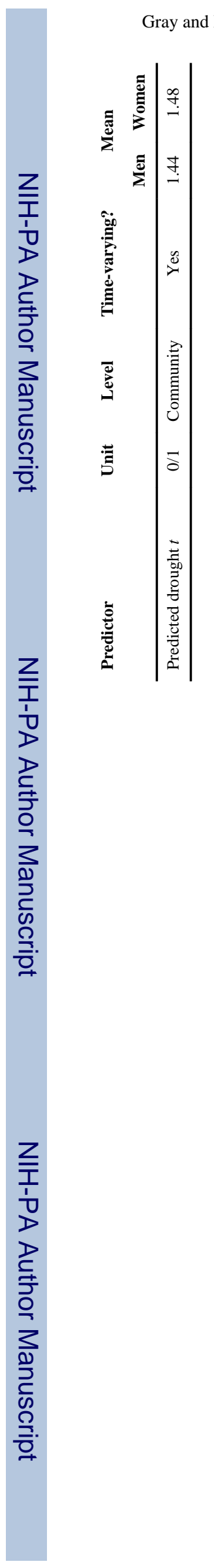

Page 19 
Table 2

Results of the dichotomous models of mobility, including odds ratios and significance tests.

\begin{tabular}{|c|c|c|c|c|}
\hline \multirow[t]{2}{*}{ Predictor } & \multicolumn{2}{|c|}{ Men } & \multicolumn{2}{|c|}{ Women } \\
\hline & Dichotomous & Interactions & Dichotomous & Interactions \\
\hline Age $15-19$ & $0.42^{* * *}$ & $0.39^{* * *}$ & $0.36^{* * *}$ & $0.37^{* * *}$ \\
\hline Age $25-29$ & $1.76^{* * *}$ & $1.81^{* * *}$ & $1.32 * *$ & $1.37^{* *}$ \\
\hline Age 30-49 & $2.16^{* * *}$ & $1.92 *$ & 0.66 & $0.56^{*}$ \\
\hline Child of head & $0.43^{* * *}$ & $0.40^{* * *}$ & $0.61^{* * *}$ & $0.53^{* * *}$ \\
\hline Has children & $0.26^{* * *}$ & $0.29^{* * *}$ & $0.18^{* * *}$ & $0.26^{* * *}$ \\
\hline Female head & 1.06 & 1.07 & 0.95 & $0.79^{+}$ \\
\hline Ethnic minority & 1.04 & 0.90 & 1.09 & 1.02 \\
\hline Parent socially important & 0.86 & 0.84 & 0.87 & 1.01 \\
\hline Head has schooling & 0.98 & 1.00 & $0.87^{+}$ & $0.80 *$ \\
\hline Household size & $1.05^{* * *}$ & $1.06^{* * *}$ & $1.05^{* * *}$ & $1.06^{* * *}$ \\
\hline Previous migrants & 1.06 & 1.06 & $1.24^{* *}$ & $1.24^{* *}$ \\
\hline $\operatorname{Ln}($ land area +1$)$ & 0.99 & 1.13 & 1.00 & 1.04 \\
\hline Livestock units & $1.04^{* *}$ & $1.06 * *$ & 0.97 & $0.96^{+}$ \\
\hline Output problems $t-1$ & 1.01 & 1.00 & 0.92 & $0.92^{+}$ \\
\hline Input problems $t-1$ & 0.99 & 0.98 & $1.11^{* * *}$ & $1.13^{* * *}$ \\
\hline Pest problems $t-1$ & $0.83^{+}$ & $0.85^{+}$ & 0.96 & 0.97 \\
\hline Flooding $t-1$ & 1.08 & 1.05 & 1.01 & 1.02 \\
\hline Reported drought $t-1$ & $1.10^{* *}$ & $1.15^{*}$ & 0.98 & 0.96 \\
\hline Drought X Age 15-19 & & 1.05 & & 0.98 \\
\hline Drought X Age 25-29 & & 0.99 & & 0.98 \\
\hline Drought X Age 30-49 & & 1.09 & & $1.13^{* *}$ \\
\hline Drought X Child of head & & 1.04 & & 1.12 \\
\hline Drought X Has children & & 0.93 & & $0.70^{+}$ \\
\hline Drought X Female head & & 0.99 & & $1.12 *$ \\
\hline Drought $\mathrm{X}$ Ethnic minority & & 1.08 & & 1.02 \\
\hline Drought X Parent socially important & & 1.01 & & $0.89^{* * *}$ \\
\hline Drought X Head has schooling & & 0.99 & & $1.06^{+}$ \\
\hline Drought X Household size & & 1.00 & & 0.99 \\
\hline Drought $X$ Previous migrants & & 1.00 & & 1.02 \\
\hline Drought X Ln(land area+1) & & $0.91^{* *}$ & & 0.98 \\
\hline Drought X Livestock units & & 0.99 & & 1.01 \\
\hline \multicolumn{5}{|l|}{ Joint tests } \\
\hline Interactions & - & $3716^{* * *}$ & - & $193^{* * *}$ \\
\hline Community fixed effects & $1 . \mathrm{E}+05^{* * *}$ & $2 . \mathrm{E}+04^{* * *}$ & $48311^{* * *}$ & $77579^{* * *}$ \\
\hline
\end{tabular}




\begin{tabular}{lllll}
\hline Predictor & \multicolumn{2}{c}{ Men } & \multicolumn{2}{c}{ Women } \\
& Dichotomous & Interactions & Dichotomous & Interactions \\
\hline Year fixed effects & $37^{* * *}$ & $51^{* * *}$ & $143^{* * *}$ & $192 * * *$ \\
$\mathrm{~N}_{\text {individuals }}$ & & 1,667 & & 1,454 \\
\hline$+\mathrm{p}<0.10$, & & & \\
$*$ & & & \\
$\mathrm{p}<0.05$, & & & \\
$* *$ \\
$\mathrm{p}<0.01$, \\
$* * *$ \\
$\mathrm{p}<0.001$
\end{tabular}

Drought $\mathrm{X}=$ Interaction with reported drought 


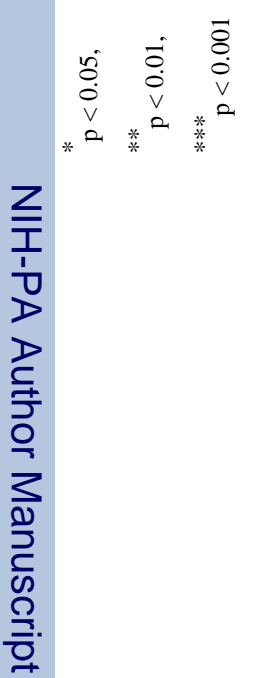




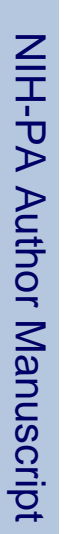

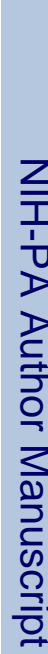

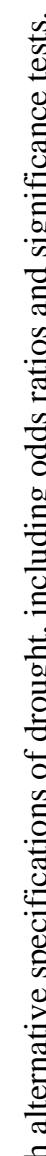

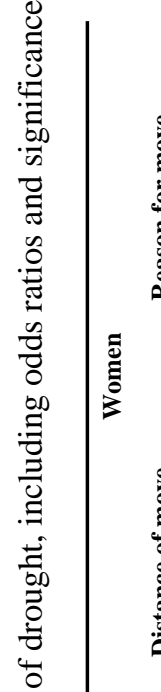

$\infty$ in $\quad \circ \quad 0$

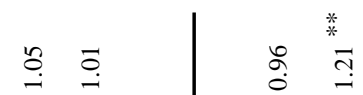

* * *

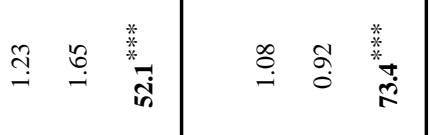

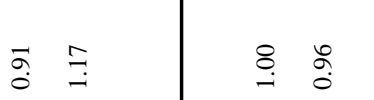

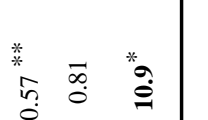

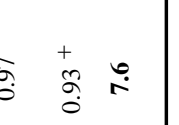

I $\stackrel{-}{2}$

ฮั.

$\underset{\infty}{\stackrel{\infty}{\infty}} \stackrel{+}{\infty} \underset{0}{\infty}$

$\stackrel{\infty}{\circ} \stackrel{0}{\circ}$

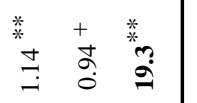

$\dddot{2}$

$\stackrel{*}{\stackrel{\infty}{1}}$

$\infty$

o.

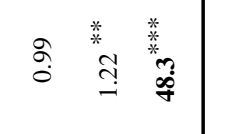

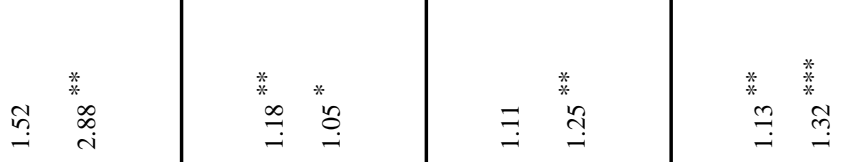

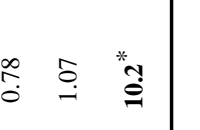

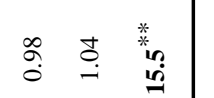

$\cong \stackrel{\overbrace{}}{=}$

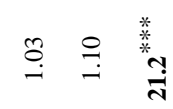

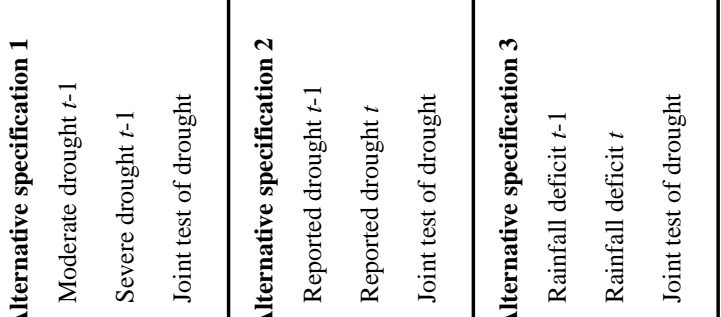

ชิ $\stackrel{-}{\circ}$

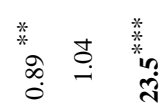

$\stackrel{+}{\stackrel{7}{\oplus}}$

$\stackrel{*}{\circ} \underset{-}{-}$

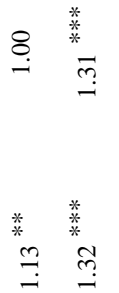

$\stackrel{+}{\infty} \stackrel{\infty}{\circ}$

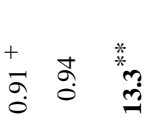

$\stackrel{8}{:}$

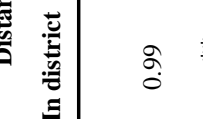

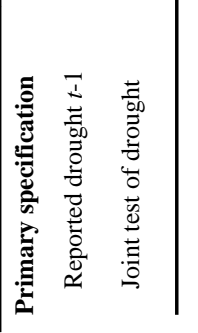

i

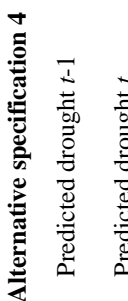

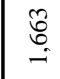

$\stackrel{5}{-5}$ 


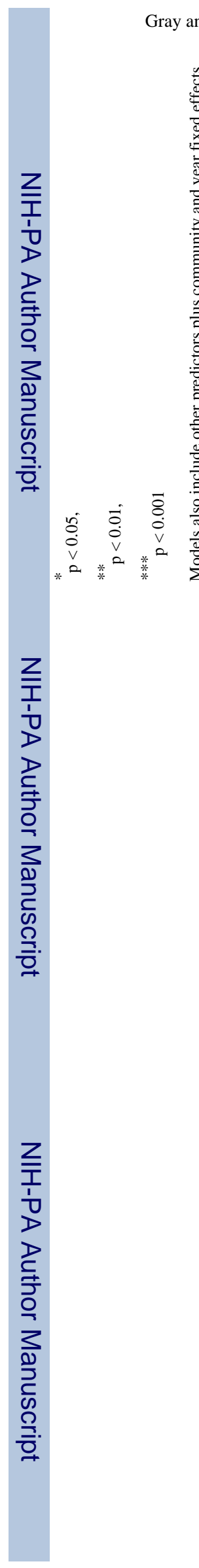

Page 25

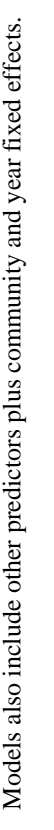




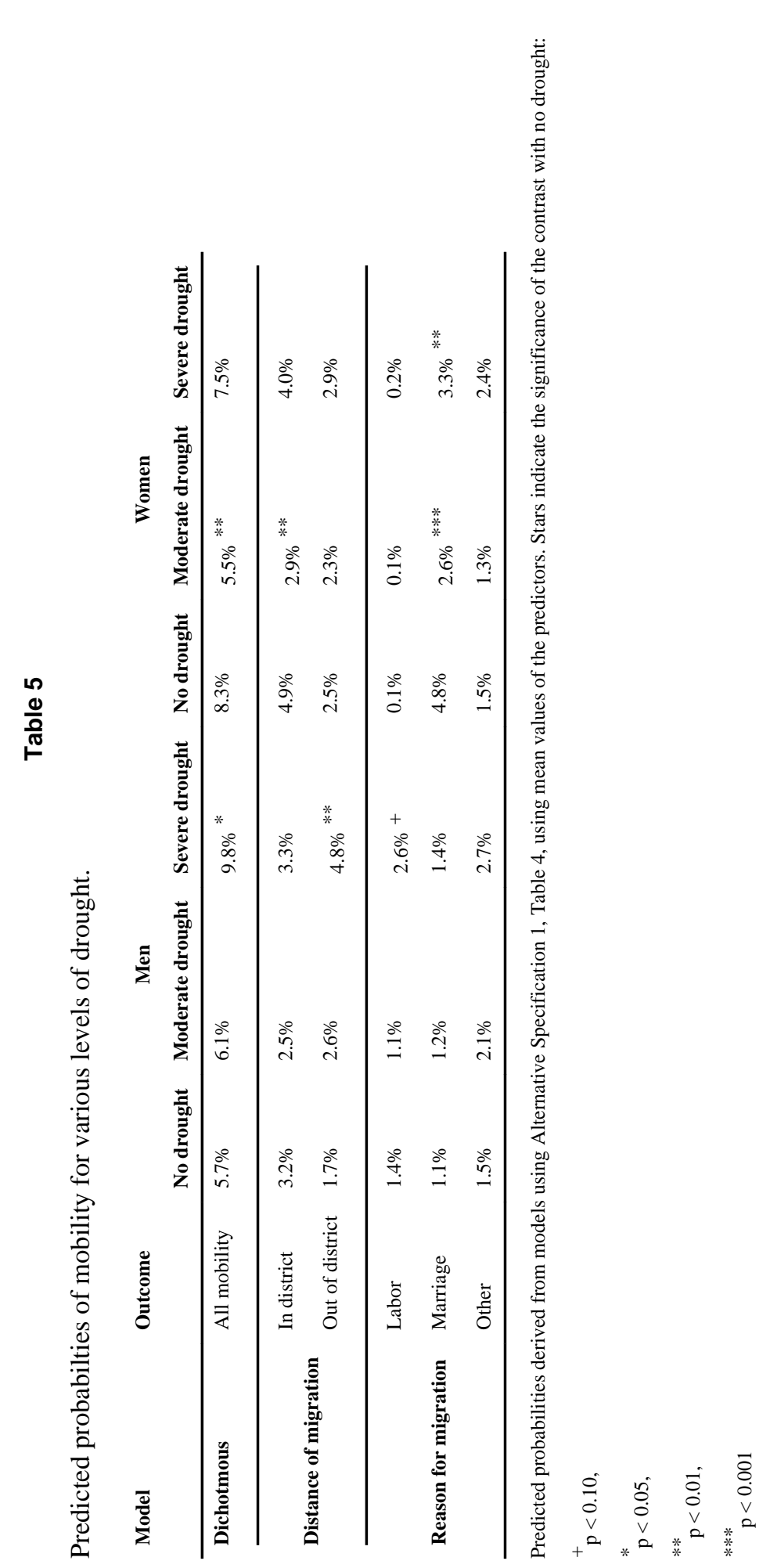

World Dev. Author manuscript; available in PMC 2013 January 01. 